\title{
THE POLITICAL ECONOMY OF PRIMARY CARE AND "HEALTH BY THE PEOPLE": AN HISTORICAL EXPLORATION
}

\author{
OSCAR GISH \\ University of Michigan, School of Public Health, 109 Observatory. \\ Ann Arbor, Michigan, U.S.A.
}

\begin{abstract}
Ahstract-The historical development of personal health services within the Third World, as background to the current discussion of primary health care and so-called "health by the people" efforts, is reviewed. This development is located within broader societal relationships, both at the national and international levels. It is argued that most of the Third World is in a state of advanced crisis characterized by static or even worsening life conditions for the mass of the population of those countries. The roots of this crisis lie in the colonial period, but contemporary national and international relationships are perpetuating essential characteristics of the inherited health care and other systems. Partly in response to this growing erisis, the narrow emphasis on growth of national product as the primary solution to underdevelopment has been largely replaced, at least in international discussion, by an approach that requires the meeting of everyone's basic human needs. In the health sector, primary health care andior "health by the people" is percejved as the major vehicle for this. The paper examines some of the issues involved in the development and application of these concepts. It is concluded that in the Third World improved health is not primarily a matter of medical systems. but rather a broader question requiring better understanding of the nature of underdevelopment itself. As a consequence. all activities concerned with health must begin with the specifics of underdevelopment in particular circumstances. Only from this background will it be possible to come to grips with the issues of improved health status as well as more relevant health and medical services in the Third World. As long as it remains essentially impossible to deal seriously with existing social and property relations, so long will it remain impossible to alter significantly the health status of the world's poorest, say, one billion people.
\end{abstract}

This paper reviews in brief, and possibly oversimplified form, the development of personal health services within the Third World, as background to the current discussion of primary care and so-called 'health by the pcoplc" efforts. The health services are seen as reflections of broader societal relationships [1]. Although the discussion is generally concerned with the "Third World". it concentrates primarily upon the former colonial territories: that is, almost the whole of the Third World except Latin America. Of course, the Latin American countries were also once colonies, but they achieved national independence approximately a century and one-half earlier and in a different historic context. And yet much of what follows could apply as well to long independent Latin America as to more recently independent Asia and Africa, which is not surprising given the similarity of their respective political systems. The discussion also does not apply to socialist Third World countries such as China or Vietnam unless specifically indicated.

\section{BACKGROLND}

During the last several years "primary care" has come to the fore as the "new" priority in health care. In September. 1978 the World Health Organization and UNICEF jointly sponsored the first International Conference on Primary Health Care which was held at Alma-Ata in the Soviet Union. The Declaration of Alma-Ata" stated that primary health care:

1. Reflects and evolves from the economic conditions and socio-cultural and political characteristics of the country and its communities and is based on the application of the relevant results of social, biomedical and health services research and public hcalth experience;

2. Addresses the main health problems in the community, providing promotive. preventive, curative and rehabilitative services accordingly;

3. Includes at least: education concerning prevailing health problems and the methods of prcventing and controlling them; promotion of food supply and proper nutrition; an adequate supply of safe water and basic sanitation; maternal and child health care, including family planning; immunization against the major infectious diseases; prevention and control of locally endemic diseases; appropriate treatment of common diseases and injuries; and provision of essential drugs:

4. Involves, in addition to the health sector, all related sectors and aspects of national and community development, in particular agriculture, animal husbandry, food, industry, education, housing, public works. communications and other sectors: and demands the coordinated efforts of all those sectors:

5. Requires and promotes maximum community and individual self-reliance and participation in the planning organization, operation and control of primary health care, making fullest use of local national and other available resources: and to this end develops through appropriate education the ability of communities to participate:

6. Should be sustained by integrated. functional and mutually-supportive referral systems. leading to the progressive improvement of comprehensive health care for all. and giving priority to those most in need: 
7. Relies, at local and referral levels. on health workers, including physicians, nurses, midwives. auxiliaries and community workers as applicable. as well as traditional practitioners as needed, suitably trained socially and technically to work as a health team and to respond to the expressed health needs of the community.

Of course. the idea and practice of primary care itself are not new. What is new is the priority such care should receive now that the international health care community has (belatedly) agreed on its importance. The significance of this recognition is great and reflects not only growing understanding of the technical, economic and social issues involved but, even more importantly, evolving political and economic relationships both within and between nations that have taken some sharp turns during recent years. Some of the most important of these relationships are touched on below.

To varying degrees, virtually all the nations comprising the "First World" of industralized capitalist countries are suffering from only slowly growing economies, relatively rapid inflation and considerable unemployment. Such economic problems inevitably carry with them certain political concerns. Most of these countries also feel the pinch of rapidly expanding and apparently uncontrollable health sector expenditures. To add insult to injury, so to speak, these expenditures are increasingly being seen as having little positive measurable impact upon even improving national health indices. Some critics have even suggested that these increased expenditures are actually contributing to ill health [2].

Most of the "Third World" [3] of underdeveloped capitalist countries is in a state of advanced crisis. This crisis is characterized by static or even worsening conditions for the mass of the population at the same time as a relative few appropriate the wealth of the nation to themselves. This process goes forward in the context of very rapidly growing and increasingly filthy urban environments, the general impoverishment of subsistence and other small peasants and farmers, unemployment and underemployment of unprecedented proportions coupled with the importation of inappropriate capital intensive technologies, rates of illiteracy that remain constant, together with growing university enrolments even in the face of graduate unemployment, and very rapid population growth flowing out of continuing poverty and inequality. All of the above has led, inevitably, to increasingly militant and revolutionary reactions and, just as inevitably, more and more unrepresentative and repressive regimes as the privileged struggle to protect their perceived interests.

Not surprisingly the health sector in most countries, including those of the Third World, follows closely the socio-political characteristics of the nation. As such, the health sector in most Third World countries is characterized by services directed toward the wealthier members of the population. and which conform to the requirements of the most elite group of health care providers. the medical profession. Coverage of the population by even elementary health care services is often no greater than a quarter of the whole, and by effective and "caring" services it is even less.
With regard to international relationships, recent years have seen not only the assertion by one group of Third World countries, the oil producers. of their right to a place in the sun, but also the defeat of the world's leading First World power. the United States. by the people of a not very large Third World country. Vietnam. And partly because of the Vietnamese experience, the United States and its associated allies have been forced to recognize the impossibility of dealing with world crises in the absence of Chinese participation. The "opening up of China" (from another view. the opening up of the Lnited States) has allowed the international establishment, in health as other matters. to hecome officially aware of the achievements of that country in eliminating the extremes of poverty and most of its associated evils within a period of only two decades starting from a base that in 1950 was similar to the rest of the Third World.

In the context of the Third World, the current primary care discussion is often translated into one of "health by the people" [4]. To a very significant degree this is based upon recognition of Chinese accomplishments in the field of health care and the fact that much of that which is required for improved health has been shown in that country to lie within the capacity of "the people" to provide for themselves. at least as part of the economic. social and political structure that prevails in People's China.

In certain critical respects the "health by the people" issue in developing countries is different from the counterpart primary care one in developed countries. This stems from the fact that although in the Third World the pattern of disease and more limited availability of resources means that primary care ought to be given higher priority than in industralized countries, the allocation of resources in such countries is frequently skewed even more towards secondary and tertiary level hospital care than it is in the richer nations. This perverse situation reflects the greater inequalities of income distribution and power that exist within most Third Worid countries, as compared to those in the First World. It also reflects the fact that the bilateral and multilateral agencies--within which so much of the rhetoric of "health by the people" has been developed-are charged. at the same time. with the responsibility of assisting developmental change directed toward greater equity in conjunction with the same regimes which often are themselves the prime obstacle to such change. In such situations even the best of aid programs may wind up benefitting primarily, or possibly even only the rich.

\section{SOME HISTORY}

\section{The colonial period}

In all probability there has never been a society without its own ways of contending with illness. Most societies have also had special persons responsible for caring for the sick. as well as their own treatment products. In fact it may still be the case that more people in the world are in regular contact with "traditional" practitioners of the healing arts than with "modern"/Western"/allopathic ones. The systems to which these traditional practitioners belong vary widely, both as to content and effectiveness. Nonethe- 
less. it can be said with some confidence that in comparing the different systems, until this century there was relatively little more of intrinsic scientific value to be found within the Western one as compared to the others. and even less so with regard to the average levels of medical practice. This was especially the case in countries such as China and India. When examining apparently less scientifically developed systems as in. say. parts of Africa. it is not all that clear that they suffer very much from comparison with the actual practice of Western medicine in rural parts of Europe or North America in the nineteenth century. At least partly because of the tendency to compare the best practice of European medicine with the average for even worstl practice of African or other systems, the latter always appear to come out very badly indeed.

The conquest of Asia. Africa and the Americas by Europe. and the consequent assumption of state power by Europeans. led to the virtually world-wide domination of European forms of organization and scientific systems [5]. Western medicine. like virtually all other things European. received official support while traditional systems either received none or were consciously suppressed. In addition, the transfer of wealth from the colonies to Europe encouraged the further rapid development of scientific and other institutions so that Western medical and other scientific systems could in fact come to outstrip those of other parts of the world.

The colonial powers began early to introduce their own medical care systems into their overseas territories [6]. In many cases these early services were developed by. and were in the charge of military personnel. Typically the pattern of "modern" medical care during the colonial era had three major components: the urban hospital. the rural dispensary-often Christian church related. and the hygiene or public health element. In essence. this remains the pattern in the Third World right up to the present.

The colonial hospital was built in the first place to meet the needs of colonial administrators and their families. and other Europeans resident in the colony. Often there was some relatively minor inpatient provision for non-Europeans [7]. These hospitals were to be found primarily in the largest centers, which were also usually the major points of European residence. There were also smaller "estate" or "plantation" hospitals, but these were more nursing institutions than anything else. The church missions also started early to build hospitals. The government hospital was a major institution in colonial life and along with the barracks or cantonment. club. etc. was essential to colonial rule. In some places in fact, the colonial medical department was a direct extension of the military or at least had immediate links with it.

The rural dispensary. like the hospital. was mainly a curative institution: primarily a place where drugs were dispensed to sick ambulatory patients. In certain respects it fulfilled the role played by pharmacies (and apothecaries) in Europe or North America at an earlier time-and sometimes still-where they diagnosed simple illnesses without charge and then sold remedies to match the diagnoses. The dispensaries were sometimes government run. in which case they often did not charge fees. but more commonly they were voluntary institutions. usually run by a Christian church body and fee charging. Many dispensaries included a few maternity or inpatient beds.

The third essential element of the colonial medical system was that of hygiene or public health. With regard to health and health care, the colonial administrator faced two major problems. The most imme* diate one was that of survival by Europeans in the hostile environments [8] of Asia and Africa, and the second the need to ensure the smooth flow of primary products such as tea, cocoa, jute and sisal, from his territory to the ships waiting at the coastal ports of the country. The first health problem was partly met by the urban hospital, and the second by the plantation dispensary. An additional measure was the introduction of the sanitary inspector of Victorian Europe into the colonial town, which was itself often a new addition to the older "native" city. The European administration attempted to separate from the prevailing environment and to create a different and cleaner one for itself. This entailed not only ensuring sanitary conditions in its own areas, but very often creating a sanitary cordon around itself in the surrounding "native" quarters. Similar hygienic efforts were made in the most important areas of primary production and estates and plantations were eventually to become more protected environments than their surroundings.

The three components described above, hospitals, dispensaries and hygiene, which comprised the colonial health care system were mixed in various ways in different places. and were often augmented by some measure of private general and nursing home practice. Naturally enough the administrators and staff of colonial medical institutions saw themselves as providing a needed service, as well as helping to introduce more scientific and orderly method into the health and health care environments of the more "backward" parts of the world. It was generally assumed that the administered peoples would prosper to the degree they became like those who administered them.

\section{Independence}

In a way the colonialists were right: those amongst the ruled who, in certain key respects, became most like their (now) former rulers were the very ones who prospered most. The two decades following the Second World War saw the national independence of most of the colonial world-Asia in the first decade and African in the second-and the third one virtually all the rest. Most countries came to independence under a leadership that envisioned orderly democratic (in the contentional western sense) development tinged with a significant element of social democracy. often within the framework of particular forms of African, Arab. Indian. etc. socialism(s).

National independence. although an historic event of tremendous significance. so far at least has not succeeded in eliminating hunger. illiteracy, the extremes of ill health and other manifestations of poverty for the bulk of the population of most Third World countries. In addition. the nations of the Third World remain heavily dependent upon economic and political decisions taken in Europe and North America. Western style democracy has broken down in most places. sometimes to be replaced by other more or less demoratic forms but. more often than not, only 
by more directly repressive regimes. In any event. with or without some semblances of "democracy". it is usual for small economic and social groups to grow rich while the majority of the population at best see no worsening of their condition.

One of the most important changes of the postindependence period has been the rapid growth of populations. mostly due to falling infant and child mortality rates. Although specific reasons for this fall are not precisely known, it is generally argued to be primarily due to public health measures such as the international smallpox and malaria campaigns, the increasing availability of supplies of clean water and improved nutritional status. Although death rates may have been affected by the smallpox, malaria, and other campaigns, the large fall that actually took place do not appear to be adequately explained by these alone, With regard to clean water, waste disposal and other aspects of sanitation, little has changed for the bulk of the population of the Third World which remains primarily rural; those who have migrated to the towns may have substantially improved their position in this respect. With regard to the nutrition factor. it may be that its important contribution to falling (especially) infant mortality rates has come about primarily through the more rapid availability of at least minimum quantities of foodstuffs at times of extreme food shortage and famine. Although famines still occur in the Third World, they are no longer so regular as they were during the colonial era. There is little evidence that average nutritional standards within much of the Third World are rising, within the context of relatively wide variations, but the very availability of national and international food stocks and the transport systems to move them quickly make it less possible under conditions of independent sovereignty to allow starvation to the point of immediate death. However. although fewer people may die outright from starvation, many survive only at lowered nutritional and energy levels; thus undernutrition becomes a chronic process rather than an acute event.

\section{Health service developments}

Most of the newly independent states embarked on the preparation of medium and long-term health development plans of one sort or another. These usually proposed the relatively rapid expansion of virtually all aspects of the health services, essentially in their existing forms. In addition, they sometimes introduced such new elements as "primary health centers" or "community participation" into the health services If these plans were in their formulation primarily only "more of the same", in application they become at best only that. and at worst allocated health sector resources even more sharply towards elite and/or urban groups and populations than had been the case before national independence.

The leaders of the newly independent countries and more particularly the medical leadership did not question the essential character of the health services they had inherited; instead. they aspired to spread these services to the whole of the population. The new services were to be "high standard", as defined by the medical elite, at the same time as they served the needs of the whole population. The very comprehensi- veness of the plans almost always meant that only a fraction of them could be implemented. thus forcing (or allowing) the implementers to single out only particular projects for development. More often than not it was the prestigious hospital plan that was thus singled out. and not the health centers, rural clinics. or preventive programs. The rhetoric of the plans was-and still is-almost always at sharp variance with proposed expenditures. The rhetoric emphasized preventive and rural priorities at the same time that expenditures were overwhelmingly curative and urban.

The plans reflect not only the social and class views and interests of the medical doctors and their political superiors who develop them. but also the narrow initial clinical training of members of the medical profession. This is not to hold Third World doctors alone as responsible for the failure of most health planning. as obviously they are part of larger structures: but. health plans often have been even "worse" than they were politically "required" to be as a result of the almost total domination of health planning by medical doctors and the related exclusion of others. The abstract "health needs" approach to planning [9] has clouded the need for explicit recognition of resource constraints to health development and consequent setting of specific priorities, inciuding the almost certain downgrading of medically cherished projects such as "that new cardiac unit". To "plan is to choose" $[10]$ and yet the system of health planning in most countries either denies the need to choose or. in some few cases, makes the planning process appear to be so complex that nothing can flow from it in any reasonable time period.

The post-independence period, then, saw a continuation of the kind of health care systems in operation during the days of colonial rule. Of course. it was an expanded system that was coming to be staffed by nationals at all levels rather than by foreigners, as well as being more readily accessible to a somewhat larger proportion of the entire population. Nonetheless the system could not be characterized as being in any basic way. other than size. as different.

With regard to size. the component parts of the system had expanded at different rates. In the first instance there was a rapid and massive expansion of medical schools, teaching hospitals and other related large hospital construction. To a significant degree these services were available only to urban populations, and the best and most expensive aspects of them only to the higher income part of that population. The output of medical schools increased rapidly and in many Asian and Latin American countries medical graduates have already become a glut on the market. Many graduates - virtually all from middle and upper class familes-have emigrated to countries such as the United States and Great Britain.

Another part of the health care system that expanded after independence was that of "public health", primarily in the form of campaigns designed to eradicate specific diseases: for example. yaws. smallpox and malaria. These campaigns were mostly vertically organized with their own administration and budgets and had relatively little contact with the rest of the health care structure. In many cases these 
special campaigns absorbed more resources than did the whole of the country's health services located outside the larger cities and towns. At least partly because of the military background of many of the early organizers of post-independence health services (especially in Asia). which followed from the pattern of colonial administration, these eradication campaigns were organized on strict military lines [11] This type of organization. while undoubtedly offering certain advantages. tends to be so costly as to raise serious doubts about the appropriateness of the entire effort. Another reason for the separate, and thus costly organizational form of the vertical campaign had been the initial external funding for many of them. This issue will be touched upon again.

The third component of the health care system, the rural dispensary, also expanded during the post-independence period. but to a much lesser degree than the other two (the medical school and related urban hospital. and special public health campaigns). Probably the most significant development in this area was that of the primary or rural health center. although the idea of the polyclinic was not new and already had been well developed in practice in the Soviet Union [12]. The Indian Bhore Committee report of 1946 set out the need for a primary health center in each "development block" (then around 60,000 people) with a group of related sub-centers. The concept was extended in East Africa [13] and later widely publicized in Maurice King's well known book [14] to the more intensive use of "medical assistants" in place of the graduate doctor. To a considerable degree this development reflected the extreme scarcity of (black) medical graduates in East and Central Africa. The concept of the rural health center with a medical assistant doing much the same work as a medical graduate is practiced widely only in a half-dozen countries of East and Central $\Lambda$ frica, and a few parts of Francaphone Africa [15]. In other countries. nurses. dispensers. and other paramedical and auxiliary personnel perform certain limited activities normally reserved to medical graduates in the industralized countries.

Independence brought with it an expansion of the health care system. along the lines discussed above. However. in certain key respects the essential model was still the colonial one (at its best) of providing "health $f o r$ the (dependent) people". In its more elaborated forms. say in East Africa. this was somewhat improved upon with the inclusion of relatcd "community participation" approaches to health care. This distinction was important. in that these broader approaches gave explicit (if often primarily rhetorical) recognition to the oneness of the community-as befitted newly independent nation-states.

External factors have much influenced the development of Third World health services. They were influential at least partly because they fitted well with already existing internal social and class interests. It is notable that many newer and more progressive health sector developments, say limitations on private medical practice being developed in the U.K.. find few advocates within the health sector in Third World countries. in spite of their newness and foreign glitter One obvious example of extcrnal influence on the development of Third World health services is the Bri- tish or American type of medical school and related teaching hospital. There is no need to elaborate here the inappropriateness (at least with regard to health care needs) of the typical Asian or African medical school [16]. Many of these schools followed the "centres of excellence" models developed by institutions such as The Rockefeller Foundations. The centres of excellence concept spread to the "teaching health center" related to the medical school, also often developed with Rockefeller Foundation or similar funding. Many centres of "excellent teaching" also became centers of "excellent research" for American and other universities. As with the teaching, the research is always excellent, even if little positive effect upon the health care needs of Third World populations can be seen to follow.

The massive eradication campaigns have also been developed largely in response to external influences, in this case program funding made available by the industralized countries, often through The World Health Organization. In keeping with this funding it was possible for donors to encourage, if not insist upon the creation of separate. vertical organization for-most notably-the smallpox and malaria campaigns. Because external funding mostly comes in the form of aid to a specific project or program, as distinct from the general health services, donors feel the need for a separate, more managerial efficient, and better monitored structure than is generally to be found in the national ministry of health. However, this efficiency is often bought only at great cost both in terms of absolute monetary expenditures and, more importantly, the overall balance of health care activities within the country. In affect, relatively small sums of external assistance often become the tail wagging the dog. Although recent years have seen a declining interest by donors in specific disease eradication programs, the approaches are now being liberally applied to family planning activities. The central lesson of the "vertical" campaign seems not yet to have been learned; namely, that given the underveloped state of national health services and their consequent inability to carry health sector programs, the only special campaigns likely to succeed would be those based upon a technology requiring only a single application-as was the case with smallpox. Of course family planning programs need not primarily depend upon the health services; however, neither should they stifle the appropriate and complementary development of those scrvices.

One unfortunate aspect of these special, externally supported activities has been the pressures they have generated which are contributing to the breakdown of one of the relatively better legacies of British colonialism; that is, a structured public sector responsibility, primarily through the ministry of health, towards the health sector as such. The problem is almost always exacerbated when the external support/intervention comes from U.S. institutions. Becausc historically American health services have primarily involved the private sector. American government intervention mainly takes the form of "special programs". Given the present incoherence of the American health delivery system [17] (except that some-mostly not patients - do very well out of it). the special program approach may be the best that can be accomplished 
at this time in the U.S. However, the imposition of such programs on countries with different and. initially at least, better structured health systems adds to the already numerous problems of appropriate health sector development.

\section{THE PRESENT}

\section{GNP dethroned}

From the end of the Second World War until the late 1960 's. the solution to Third World underdevelopment was seen to lie in a relatively rapid growth of national product leading to a gradual amelioration of the situation of the mass of the population. In keeping with this view. "nonproductive" expenditures such as those for health were to the greatest degree possible to be limited: not that in practice they always were, but this was held to be the desirable goal. The narrow, growth of GNP orientation of the post-war period. perhaps particularly on the part of American development economists, gave strong support to the argument that as little as possible-at least within existing political constraints--should be spent (or rather sunk) into the "bottomless pit" of heaith and other social sector needs, at least until national economies were strong enough to provide needed support to such programs. This approach was justified by the historical experience of western Europe and the U.S., areas which had experienced their own economic development during the late 18 th and 19 th centuries.

The decades of the 1950's and 60's were relatively successful in terms of economic developmentdefined narrowly as growth of national product-- in that few of today's industralized countries had ever experienced comparable rates (Eastern Europe and Japan are notable exceptions). Of course, much of this growth was uneven and some countries saw very little indeed, while others experienced much more. During this period little attention was paid to the question of the distribution of this growth, both between and within countries, and relatively (or very) wealthy elite social classes became established in most developing countries at the same time as the mass of the population were at best not becoming poorer. It is difficult to document these developments precisely, as reliable data about income distribution in developing countries were scarce until the late 1960's; this was not a matter of accident. but rather a reflection of then current development priorities.

Most of the countries of the Third World experienced a decline in their mortality indices during this period. These declines related not only-or perhaps not even primarily--to the decreasing incidence of some communicable diseases, but also to the fact that during time of food shortage and famine central governments could move foodstuffs around quickly enough to prevent the deaths of millions. In any event. Third World improvements in health status during the 50's and 60's owed relatively little to the organized health services, except as parts of them were reconstituted into a few categorical programs. In addition, in spite of falling death rates particularly amongst children, it is likely that average nutritional (and possibly even overall health) status in many Third World countries worsened during the two decades of relatively rapid growth of the 1950 s and 60 's; that is, there was a decline in the average consumption of food grains - which are the major source of subsistence of Third World populations--for the lower one to two-thirds of the population.

By the middle and late $1960^{\circ} \mathrm{s}$ there was increasing disillusionment about "growthmanship" as the appropriate development model for most countries. It is worth noting that in the late $60^{\circ}$ s the suitability of continued growth as a model for the developed countries also came under question and the early 70 ' $\mathrm{s}$ saw the phenomenal success of a book such as Schumacher's Small is Beautiful[18]. One intellectual turning point of some significance with regard to the "dethroning of GNP" as the single most important development indicator was the speech given by Dudley Seers, then President of the Society for International Development, at the Presidential Luncheon of the annual meeting of the society in New Delhi in 1969 [19]. Seers suggested three more appropriate measures of development than simply growth of GNP: improved nutritional status, greater possibilities for employment or at least control over one's own productive capacities and output e.g. more equitable land tenure systems, and increasing equality between groups and social classes within and between countries Since 1969 these and other related issues have increasingly been accepted as the "new conventional wisdom" about the problem of underdevelopment.

\section{Health by the people}

The emergence of a new majority view of development focused upon the needs of the most impoverished, including perhaps especially their nutritional and health requirements, has more or less "swept the development boards". Opposition continues to be voiced hy more traditional development economists and, on the other side of the ideological coin. those who argue that only fundamental politicalistructural changes can positively affect (in this case) the health status of the world's poor. In fact. it is argued that in the absence of more fundamental changes. the very programs justified originally by the tragedy of the poor may benefit only the rich. The related new health care strategy which has emerged is based upon the provision of primary health care for all. although "provision" is perhaps not quite the right word, as the new approach calls for popular participation in the creation and implementation of health campaigns and services, or health "by the people" as opposed to health "for the people". These primary health care and related health by the people strategies. in their more carefully elaborated forms. relate changes in the ongoing health care system to such innovations as the use of village level workers and indigenous practitioners. Yet most current health by the people activities appear only as "projects"; that is, isolated activities carried out apart from overwhelmingly hospital based delivery systems which absorb virtually the whole of health ministry budgets. Although data are not available. there is no reason to believe that the "new primary care approach" has (yet:) had any measurable effect upon the spending priorities of Third World ministries of health. In fact. based only on anecdotal evidence, it could more persuasively be 
argued that hospital-oriented health sector expenditures as a percentage of the whole are at best stable, while in many places they are rising.

One important difficulty with the health by the people approach at least as popularized by international agencies. is the failure to distinguish between so-called "alternative approaches" [20] in countries such as China, Cuha and Tanzania which are directed toward overall changes both within the health sector and in the broader national context and small, isolated individual projects often externally financed, taking place in countries with governments having little or no orientation toward the overall health care needs of the population. Although certain techniques can be applied in both "special" local situations and as part of overall national change. the substance of the matter differs in such varied contents; to characterize and group such different situations under the one heading of "alternative approaches" is unjustified. Although many individual projects may in time have a growing positive cumulative effect. the present reality is different. In any event. historical experience is not such as to encourage optimism. In the short run at least. the "alternatives" confusion indicated above may only contribute to letting some governments and health ministries "off the hook". The preoccupation with special health by the people projects diverts attention away from the inappropriateness of the existing health care system. and not only for the support of health by the people efforts but even the more prosaic health "for" the people approaches.

\section{CONCLLSION}

\section{Health with the people [21]}

The current discussion about the development of various forms of village health workers, utilization of traditional practitioners. the needs of nomadic populations. etc. in the context of health by the people must be welcomed. However, as yet the discussion has been marked more by wishful thinking at best and cynicism at worst, than by hard analysis of the issues involved. It seems not to be appreciated that barefoot doctors and indigenous practitioners are unlikely to be extensively developed and properly utilized in the absence of fundamental reforms of the more conventional health delivery systems. Such cadres could not function properly in isolation or in the absence of the support that can only be given by a reformed health care system. The discussion appears to have moved in remarkably short order from almost total rejection of the traditional practitioner. the village health worker or even other types of "medical practitioners" than those with university degrees to idyllic glorification of these types of cadres. However, the argument in favor of the use of traditional practitioners does not question why even "modern" practitioners of private medicinc have not been properly integrated into Third World health care services: or with regard to the use of village medical helpers. the problem of financial remuneration for such groups in the absence of Chinese type societal relationships: or why it is that the poor with relatively good access to existing health services. as opposed to the concern about those who do not. find them so unsatisfactory in meeting their basic requirements. Problems such as these (and more findamental ones too) must be solved if the health by the people approach is to become more than simply rhetoric built around a number of special projects.

In many respects a false distinction has been drawn in the contrast between health "by" and health "for" the people. On a significant scale it will not be possible for there to be health "by" the people unless their governments also provide health "for" the people. Emphasis must be placed on necessary changes in existing health care systems that all too frequently destroy the health care possibilities of the many, at the same time as new ways develop to involve thr community in its own health and health care system This combination can be termed "health with the people".

The limitations of conventional health care systems are obvious. The narrowly technological approach to health care serves to block the integrated utilization of health. economic and other resources. In fact. highly professionalized and technological health services cannot be equitably distributed as it is neither possible nor desirable to have a hospital in every village. The task rather, is to attempt to change he composition of health services-away from hospitals and towards primary care-through their more equitable distribution, and to make them part of overall economic and social development.

What then can "the people" do in the context of a "health with the people" approach: A schema containing a few examples follows:

1. As individuals: lead healthier lives, e.g. exercise, no addictive habits, etc.

2. As a "health care" community: create health care service resources, e.g. "barefoot doctors", organize campaigns designed to destroy disease vectors, etc.

3. As a "political" community: control the health care system and the professional "providers" of health care, control the overall socio-economic system, etc.

The current disillusionment with existing health delivery systems that now exists in so many quarters should not be allowed to become the basis of a twotier health care system (at best), one for the minority with access to an extensive high technology system and one (or perhaps none) for the rest of the population. The basic and legitimate concept of health by the people could be hindered if the types of special projects discussed above continue to be identified as "the primary health care strategy"; in the absence of change in the whole of health care systems (if not entirc political structures) they can only lead to disappointment and frustration. It must be stressed that the major obstacle to more just and efficient health care systcms (whether "by", "for" or "with" the people) are not the usually cited ones of limited resources, poor communications. or lack of technological knowledge and data, but rather social systems that place a low value on the health care needs of the poor. This is especially the case when the satisfaction of those nceds may require certain adjustment. thought to be uncomfortable in the short-run at least. in the behavior of the professionals who provide the health services. and of the elite who monopolize the best of that which is provided. 


\section{POSTSCRIPT}

It is becoming increasingly clear that in the Third World improved health is not primarily a matter of medical systems, but rather a broader question requiring better understanding of the nature of underdevelopment itself. As a consequence, all activities concerned with health must begin with the specifics of underdevelopment in particular circumstances. Only from this background will it be possible to come to grips with the issues of improved health status as well as more relevant health and medical services in the Third World. As long as it remains essentially impossible to deal seriously with existing social and property relations, so long will it remain impossible to alter significantly the health status of the world's poorest, say, one billion people.

Given the fears now existing in the richer parts of the world, and amonst many of the better off in poor countries. over the interrelated issues of continued underdevelopment. population growth, the environment, and "spaceship earth" makes it all the more remarkable that the issues of inequality and oppression as the basic causes of the growing world crisis can continue to be put aside. Although the poor have always lived in ecological crisis, their increasing numbers are now bringing that crisis to the better off, whether in the wealthy suburbs of Manila or in the United States. The so-called "soft state" which supposedly characterizes most developing countries has not been notably soft in the defense of privilege and in too many cases appears to be moving. in the name of world ecological balance, toward coercion on the population issue of a sort that would have been unthinkable only a lew years ago.

At the end of the Second World War the full exposure of racial genocide, including forcible sterilization, in Europe shocked the entire world. At that time any justification of compulsory sterilization (other than on very special medical grounds) would have been universally condemned. Only a little over thirty years later it has become possible to come dangerously close to open proposals for forcible sterilization, although (implicitly) based on class (for the poor) and not on race, as was the case in World War II [22]. This alternative is preferred or at least appears to be more viable, to those who propose it to tampering with existing class and property relationships which in the first place are at the root of the crisis. It is frightening to contemplate, but George Orwell's 1984 is more likely to be the year in which the poor were forcibly sterilized-probably with the support of the world's democracies - as an alternative to a basic resw tructuring of existing maldistributions of property, wealth and power, and the ensuing threat of some sort of socialism or communism. than the year in which we all came to lose our liberties to some totalitarian "Big Brother" of the left. Perhaps it need not be so, but history appears to teach that the powerful never give up anything without being forced to.

Acknowleduments-Very helpful comments were received from Professors Finkle. Grosse. Wegman and Wylie of the School of Public Health. University of Michigan: Dr $S$. Joseph then of the School of Public Health. Harvard University: Ms S. S. Russell of Westinghouse Health Systems;
Professor V. Sidel of the Department of Social Medicine. Montefiore Hospital and Medical Center: and Professor $G$. Silver of the School of Medicine. Yale University

\section{REFEREYCES}

1. V. Navarro's seminal contributions The underdevelopment of health or the health of undevelopment. $/ \mathrm{m} . J$. Hith Sirt, 4, 1974 and What does Chile mean: An analysis of events in the health sector before. during and after Allende's administration. Milbank mem. Fund 4. bull. 52, 1974. are concerned with these relationships in a far more precise way. Also for an excellent discussion of the issues within the Indian context, see Banerji D. Social and cultural foundations of health services systems. Econ. Polit. Weekly: Special Number. August 1974.

2. For example: Mlich I. Medical Vemesis. Pantheon Books. New York. 1976

3. Industralized socialist countries (the "Second World") will not be dealt with. partly because the issues there are quite different. but mainly because the priority importance of primary health care has always been recognized both in theory and practice in these countries.

4. The expression has become widely known through the World Health Organization book of the same title. edited by K. Newell. Geneva, 1975.

5. For example. see Rodney W. How Europe Underdere'oped Africa. Howard University Press. Washington. D.C. 1974.

6. In fact, at least in some cases. the introduction of medical missionaries even preceded the coming of the flag. For example the famous explorer Dr. Livingston ("I presume") was a medical doctor.

7. In older. now usually expanded regional and district hospitals in Africa the former European ward is now often reserved (on a non-segregated basis) for "Grade I" patients.

8. Hostile not especially because of so-called tropical diseases. but the very poor socio-economic conditions of the mass of the people and the related low sanitary standards which allowed (and continue to allowi these diseases to flourish.

9. The so-called "needs based" approach to planning does not begin to consider resource constraints (if ever) until after a full set of "needs" have been determined. and then mostly separately from them. A "resource based" approach will from the outset of the planning exercise accept the reality of limited resouress and the need to allocate them in keeping with the priority requirements and possiblities of the entire community.

10. As President Nyerere of Tanzania constantly reminds his planners.

11. For more on this, see Banerji's excellent contribution. referred to earlier.

12. Roemer M. 1. Urganized ambulatory health service in international perspective. IH. J. Hith Sert. 1, 1971.

13. Fendall N. R. E. Medical planning and the training of personnel in Kenya. J. trop. Med. Hy. 68, 1965.

14. King M. Medical Care in Developing Countries, Oxford Univ. Press. 1966.

15. Gish O. Planning the Health Sector, The Tanzanian Experiences. Croom Helm, London. 1975 and 1978 (reprinted).

16. Of course. this is also true to a very considerable degree of medical schools in the industralized countries.

17. No federal level ministry of health even existed in the United States until the early 1950 s. and and in many key respects it is still not one that can be compared to those in other parts of the world.

18. Schumacher E. F. Small is Beautiful. Harper \& Row. 1973. 
19. Seers D. The meaning of development. Int. Devel. Ret. XI. 1969.

20. As in Djukanovich V. and Mach E. P. Alternatite Approaches to Meeting Basic Health Needs in Developing Coumtries. World Health Organization. Geneva. 1975.

21. This expression was coined in 1974 by a group (of which the author was part) then working at the Institute of Development Studies, University of Sussex.

22. See Banerji D. Will forcible sterilization be effective. Econ. Polit. Weekly 11, 1977: Minkler M. Thinking the unthinkable: The prospect of compulsory sterilization in India. Int. J. Hlth Sert. 7, 1977. 